\title{
AVALIAÇÃO DA ESTEREOSCOPIA SAR (STANDART-RADARSAT-1) E HÍBRIDA (STANDART-RADARSAT-1 \& TM-LANDSAT-5) EM MAPEAMENTO GEOLÓGICO NA PROVÍNCIA MINERAL DE CARAJÁS
}

\author{
ATHOS RIBEIRO DOS SANTOS, WALDIR RENATO PARADELLA \& PAULO VENEZIANI
}

\begin{abstract}
EVALUATION OF THE SAR (Standard-RADARSAT-1) AND HYBRID SENSORS (Standard-RADARSAT-1 \& TMLANDSAT-5) STEREOSCOPIES FOR GEOLOGICAL MAPPING IN THE CARAJAS MINERAL

PROVINCE. This paper discusses the theoretical and practical aspects related to SAR and hybrid sensors (VIR - Visible-Infra Red x SAR - Synthetic Aperture Radar ) stereoscopies, and their performance for geological mapping in the Amazon Region. Stereo Standard-RADARSAT-1 (S5D x S7D) and hybrid Standard-RADARSAT-1/TM-Landsat-5 (S7D x TM4) were visually evaluated aiming at geological mapping in the Carajás Mineral Province. The stereo SAR pair has shown large differences in radiometric and geometric properties when compared to the VIR x SAR stereo pair. The investigation has also demonstrated that these differences play a key role in the extraction of geological information and also confirmed that previous background in SAR and radargrammetry are fundamental issues in the composition and interpretation of the SAR and hybrid products. The research has indicated the greater potentiality of the VIR x SAR product when compared to the SAR stereoscopy. The complementary nature of the information provided by both sensors in distinct region of the electromagnetic spectrum was a fundamental cause for this better performance.
\end{abstract}

Keywords: geologic remote sensing, SAR and VIR x SAR stereoscopies, Carajás Mineral Province.

\begin{abstract}
Resumo Este artigo discute os aspectos teóricos e práticos relacionados às estereoscopias de radar e híbrida (VIR - Visible - Infra Red x SAR - Synthetic Aperture Radar) e suas performances para o mapeamento geológico na região Amazônica. Estéreo - pares Standard-RADARSAT-1 (S5D x S7D) e híbrido Standard-RADARSAT-1/TM-Landsat-5 (S7D x TM4) foram avaliados visualmente objetivando o mapeamento geológico na Província Mineral de Carajás. O estéreo-par SAR mostrou grandes diferenças em propriedades radiométricas e geométricas, quando comparado ao estéreo-par VIR x SAR. O estudo também demonstrou que essas diferenças desempenham um importante papel na obtenção de informações geológicas, e confirmou, ainda, que o conhecimento prévio em SAR e radargrametria é fundamental na composição e interpretação dos estéreo - pares SAR e híbrido. A pesquisa indicou uma maior potencialidade aos produtos VIR x SAR, quando comparados à estereoscopia SAR. A natureza complementar das informações fornecidas pelos sensores, em regiões distintas do espectro eletromagnético, foi a causa fundamental da melhor performance do estéreo - par híbrido.
\end{abstract}

Palavras-chaves: sensoriamento remoto geológico, estereoscopias de radar e híbrida, Província Mineral de Carajás.

INTRODUÇÃO Durante muito tempo os dados ópticos e de radar foram utilizados de modo independente e monoscopicamente, porque a estereoscopia não era uma ferramenta disponível, ou muito limitada, nos primeiros sensores orbitais. Mais recentemente, a disponibilidade do formato digital, tanto dos dados ópticos como das microondas, levou ao desenvolvimento de técnicas que permitem a integração desses conjuntos de dados nos chamados produtos multifonte (Harris et al. 1994, Paradella et al. 1997). Apesar do estabelecimento dos conceitos básicos da radargrametria e dos primeiros experimentos sobre estereoscopia de radar terem ocorrido já na década de 1960 (La Prade 1963), somente com o advento do radar de abertura sintética ou SAR (Synthetic Aperture Radar) do satélite canadense RADARSAT-1 em 1995, que a estereoscopia de radar passou a ser estudada, entendida e aplicada (Toutin \& Vester 1997, Santos et al. 1999). Só recentemente, devido à maior disponibilidade de dados SAR, foram publicados os primeiros resultados de avaliação da aplicabilidade de pares estereoscópicos híbridos na fusão tridimensional de imagens orbitais SAR e ópticas (Toutin 2000, Santos et al. 2001).

Neste sentido, este trabalho teve como objetivos a análise e a comparação de dois pares estereoscópicos, sendo um de radar orbital (Standard-RADARSAT-1) e outro híbrido (StandardRADARSAT-1 \& TM-Landsat-5), para fins de mapeamento geo- lógico na Amazônia. Os dois estéreo-pares utilizados foram selecionados a partir da análise dos diversos aspectos teóricos que envolvem a estereoscopia de radar e a híbrida, com o intuito de obter a melhor performance em interpretações geológicas, considerando-se as particularidades da área de estudo (relevo, vegetação, ambientes geológicos, etc.). Os pares foram interpretados geologicamente e as diferenças entre os resultados explicadas com base nas características de cada estéreo-par: similaridade radiométrica (determina a visibilidade estereoscópica), disparidade geométrica (determina o detalhe de percepção de profundidade), contribuição temática de cada uma das cenas (determina as variações tonais/texturais), etc. Mais do que uma análise sobre o volume de informações potenciais em cada conjunto de dados, o estudo buscou estabelecer, principalmente, as contribuições e as restrições da análise múltipla de dados (SAR x óptico), em relação à estereoscopia de radar.

A área de pesquisa, localizada na região central da Província Mineral de Carajás, foi escolhida não só pela sua importância geoeconômica, mas pela diversidade de ambientes geológicos e de relevos (a geometria superficial é a principal condicionadora no retroespalhamento das imagens SAR); pelo condicionamento geobotânico (Paradella et al. 1994), associado à variações topográficas/unidades geológicas (a resposta espectral do sensor 
óptico é principalmente condicionada pelas características físicoquímicas dos materiais superficiais) e; pelo ambiente de floresta tropical úmida, onde as dificuldades de acesso e o profundo intemperismo tornam o sensoriamento remoto uma ferramenta imprescindível na obtenção de informações geológicas.

SÍNTESE GEOLÓGICA A Província Mineral de Carajás situase na porção sudeste do Craton Amazônico, estável desde o final do Pré-Cambriano (Almeida et al. 1981). Dois importantes modelos tectônicos foram propostos para a área, respectivamente, por Cordani \& Brito Neves (1982) e Teixeira et al. (1989), e por Hasui et al. (1984) e Hasui \& Haraly (1985). O primeiro, baseado em dados geocronológicos, identifica cinturões móveis proterozóicos ao redor de um núcleo cratônico arqueano. Os gnaisses e as rochas metavulcânicas e metassedimentares da Serra dos Carajás são associados à Província Amazônia Central, do Paleoproterozóico/ Arqueano. O segundo modelo, baseado em dados geofísicos e estruturais, propõe um arcabouço tectônico para o Craton Amazônico formado por blocos crustais arqueanos, com limites caracterizados por anomalias gravimétricas positivas, fortes variações magnéticas e trends lineares das estruturas tectônicas. Seqüências vulcano-sedimentares e corpos graníticos são comuns nestes blocos.

A primeira grande síntese e revisão litoestratigráfica regional sobre a Província Mineral de Carajás foi feita por DOCEGEO (1988). O estudo definiu três unidades principais: (1) Complexo Xingu, composto por gnaisses tonalíticos à granodioríticos e metasupracrustais; (2) Supergrupo Itacaiúnas, composto pelos grupos Grão Pará (rochas metavulcânicas e metassedimentares) e Rio Fresco (metarenitos) e; (3) granitos proterozóicos.

Araújo \& Maia (1991) definiram para a região o Cinturão de Cisalhamento Itacaiúnas, de idade arqueana, com três domínios litoestruturais: (1) Meridional, caracterizado por zonas de cisalhamento imbricadas que afetaram as rochas dos complexos Xingu e Pium, da Suite Plaquê e do Grupo Sapucaia; (2) Central, de natureza direcional (mecanismos do tipo strike-slip e flor positiva), composto pelos sistemas Serra dos Carajás, Cinzento, Tapirapé e Buritirama, e; (3) Setentrional, caracterizado por cavalgamentos, com rochas granulíticas misturadas tectonicamente ao Complexo Xingu e, subordinadamente, seqüências metassedimentares. Idades radiométricas de 1,88 Ga. correspondem a granitos anorogênicos (Machado et al. 1991, Dall'Agnol et al. 1999).

Pinheiro (1997) e Pinheiro \& Holdsworth (2000) subdividiram tectono-estratigraficamente a região dos sistemas de cisalhamento Carajás e Cinzento em: (1) Assembléia Embasamental, constituída por rochas do Complexo Xingu e Grupo Igarapé Salobo, submetidas à deformação dúctil e metamorfismo de alto grau e; (2) Assembléia de Cobertura, constituída por rochas vulcano-sedimentares de baixo grau, deformadas por cisalhamento dúctil à dúctil-rúptil (grupos Igarapé Pojuca e Grão Pará) e rochas clásticas da Formação Águas Claras (deformação rúptil). Segundo os autores, a história estratigráfica e tectônica da região é marcada por, pelo menos, quatro episódios de deformação.

Veneziani et al. (2002), mediante a interpretação de dados de sensoriamento remoto orbital (RADARSAT-1 e TM-Landsat-5), de aerogeofísica regional (gamaespectrométricos), de campo e de literatura, caracterizaram os movimentos tectônicos em parte do Cinturão de Cisalhamento Itacaiúnas, na região de Carajás. Os autores identificaram três fases transpressivas (localmente transtensivas) de cisalhamento e uma transtensiva, durante o Arqueano-Paleoproterozóico. A primeira fase, caracterizada por movimentos transpressivos sinistrais ao longo da direção principal do cinturão (WNW-ESE), está registrada pela trama milonítica nas rochas do Complexo Granítico-Gnáissico e nos grupos Igarapé Salobo e Igarapé Pojuca. A segunda fase foi marcada por movimentos destrais oblíquos, de médio a alto ângulos, em torno da direção principal. Esses movimentos deformaram de forma dúctil a rúptil as estruturas da primeira fase e, nas regiões transtensivas, originaram rhombo-chasms e releasing bends com embaciamento, sedimentação e/ou vulcanismo e granitogênese (grupos Grão Pará e Buritirama, Gabro Santa Inês, Complexo Granítico Estrela e, possivelmente, Formação Águas Claras). A terceira fase, transpressiva sinistral ao longo de WNW-ESE, gerou deformações rúpteis a rúpteis-dúcteis que afetaram rochas desde o embasamento até a Formação Águas Claras. Estruturas transtensivas locais (rhombo-chasms e releasing bends) provocaram um adelgaçamento crustal, proporcionando, posteriormente, condições para a ocorrência de granitogênese (granitos Central, Cigano, etc.), embaciamento e sedimentação (Formação Gorotire) e magmatismo básico. Seguiu-se uma fase de acomodação, com componente de movimentação destral rúptil, de rejeitos decimétricos, observada inclusive nas bordas do Granito Cigano (Paleoproterozóico). Essas mesmas direções sofreram reativações distensivas posteriormente, com picos no final do Proterozóico (Grupo Serra do Paredão), no Mesozóico (intrusivas básicas) e no Terciário.

PROVÍNCIA MINERAL DE CARAJÁS A área de estudo faz parte desta província mineral e engloba partes da Serra dos Carajás e de seu entorno (Fig. 1). A Serra dos Carajás destaca-se na topografia, com o seu relevo montanhoso e dissecado em escarpas, com altitudes de até 800 metros. É constituída por sedimentos (Formação Águas Claras) e rochas vulcano-sedimentares de baixo grau (Grupo Grão-Pará), de idades arqueanas. No centro da Serra ocorre um batólito granítico proterozóico (Granito Central), com um relevo colinoso e altitudes de 450 a $500 \mathrm{~m}$. No entorno da Serra predominam as rochas gnáissicas arqueanas do Complexo Xingu, em um relevo arrasado, com altitudes de 200 a 300m.

FUNDAMENTAÇÃO As imagens orbitais de radar são importantes ferramentas na obtenção de informações geológicas da Amazônia Brasileira (Paradella et al. 1997, 1998; Santos et al. 1999), pela sua sensibilidade às características geométricas e elétricas da superfície e operação sob condições atmosféricas adversas ao imageamento óptico, pois, de acordo com a freqüência adotada, o imageamento SAR é parcial ou totalmente invisível aos efeitos de bruma, nuvem, chuva e fumaça. $\mathrm{O}$ excelente realce da topografia do relevo nas imagens SAR orbitais resulta do imageamento sob visada lateral, com possibilidades de variação de incidências e de azimutes de iluminação. Por outro lado, as imagens ópticas fornecem informações sobre as propriedades físico-químicas dos materiais superficiais. $\mathrm{O}$ imageamento no espectro óptico, em grande parte da Amazônia, só é normalmente possível em época com condições atmosféricas mais favoráveis, de maio a setembro, quando o ângulo de elevação solar é elevado e há pouca variação no azimute solar. Isto resulta em realce modesto na topografia do relevo (pouco sombreamento), particularmente nas regiões mais arrasadas. As informações registradas em ambos tipos de imagens são, portanto, distintas e complementares. Especificamente na região de Carajás, as informações obtidas pelo SAR se relacionam à geometria de iluminação (incidência e azimute) e à interação das microondas (banda $\mathrm{C}-\mathrm{HH}$, no caso deste trabalho) 


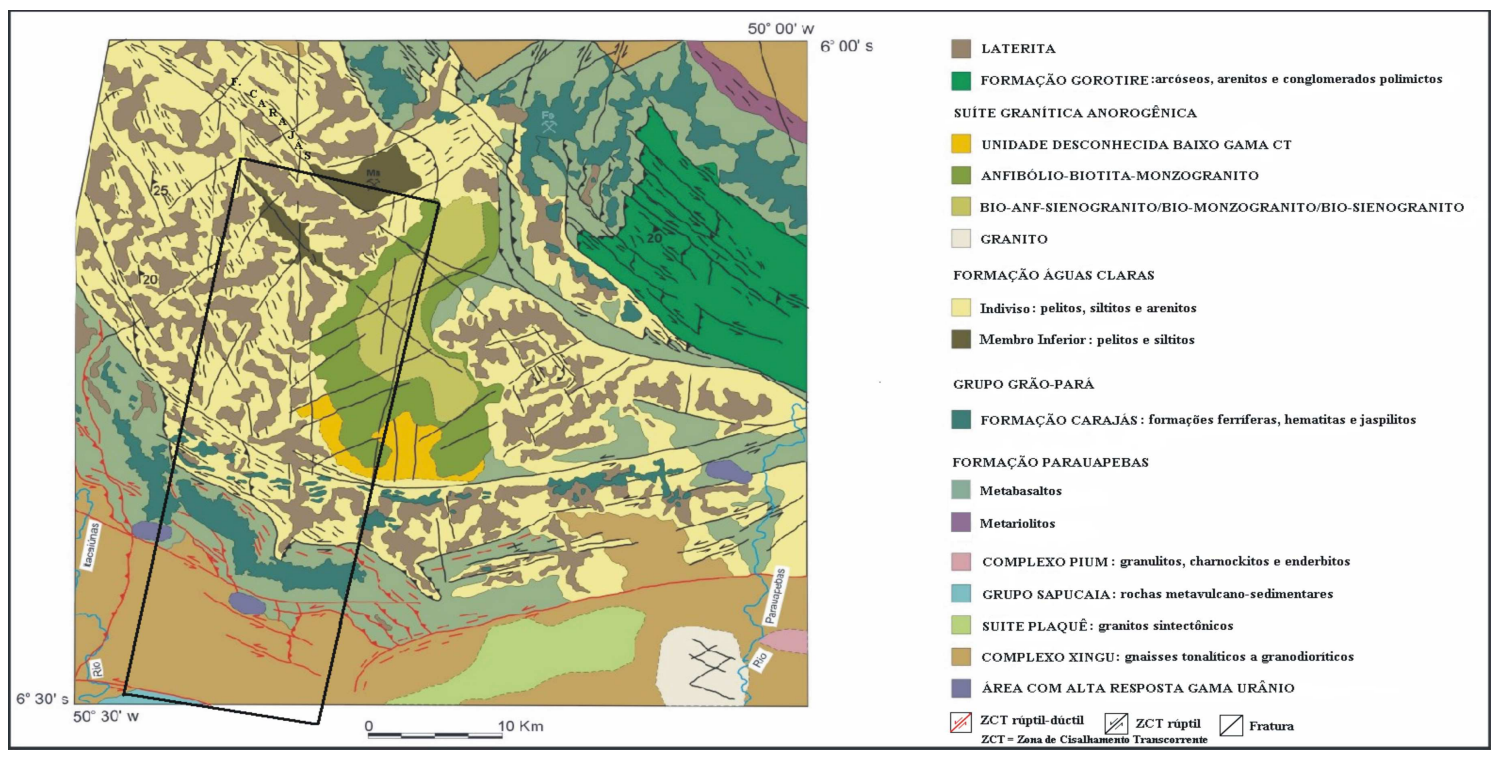

Figura 1 - Mapa Geológico da Folha Serra dos Carajás e localização da área de estudo (fonte: Paradella et al. 1998).

com a parte superior do dossel vegetal da floresta equatorial ombrófila densa. Em se tratando das imagens ópticas (TMLandsat-5, no caso deste trabalho), a informação detectada (radiância) é controlada pelo espectro da floresta e pela orientação topográfica do terreno em relação à fonte solar (Paradella et al. 2000).

Há, basicamente, duas formas de combinar diferentes dados de sensoriamento remoto em uma análise conjunta. A fusão digital utiliza técnicas de integração (Harris et al. 1994, Paradella et al. 1997) que permitem, a partir de duas imagens geometricamente registradas, obter um produto final que congregue o melhor das informações de cada conjunto de dados originais. A estereoscopia (óptica, de radar e híbrida), por sua vez, utiliza-se de conceitos desenvolvidos a partir do entendimento da visão humana, para permitir que diferentes conjuntos de dados de sensoriamento remoto, representados por duas imagens planas, sejam analisados conjunta e tridimensionalmente. Apesar dessa fundamentação básica única, há importantes aspectos relacionados aos dados ópticos e aos de radar, que diferenciam amplamente as estereoscopias óptica, de radar e híbrida (detalhes da estereoscopia SAR e híbrida SAR x óptico utilizando imagens orbitais podem ser encontrados, por exemplo, em Toutin \& Vester 1997, Santos et al. 1999, Toutin 2000 e Santos et al. 2001).

Há, na estereoscopia, dois importantes indicadores de performance que apresentam comportamentos díspares quando se analisa separadamente os dados ópticos e os dados SAR. A correlação radiométrica entre as cenas do par (qualidade ou conteúdo temático: tom, textura, etc.) está diretamente relacionada à visibilidade estereoscópica, que determina a maior ou menor facilidade de percepção de profundidade em um par. A disparidade geométrica entre as cenas do par (diferentes perspectivas de imagear a mesma cena) está diretamente relacionada à paralaxe, que determina o nível de detalhe na percepção de profundidade. É desejável, portanto, que as cenas de um par estereoscópico tenham alta correlação radiométrica (boa visibilidade estereoscópica) e grande disparidade geométrica (maiores paralaxes). Nos sistemas ópticos, as alterações de geometria que resultam na paralaxe necessária à visão tridimensional, não implicam em mudanças significativas na iluminação das cenas. $\mathrm{O}$ radar imageador tem a sua própria fonte de iluminação, o que significa que, quanto maiores as diferenças geométricas entre as cenas do par (obtidas pelas alterações da geometria de visada), maiores serão as diferenças radiométricas entre elas. Ao contrário dos sensores ópticos, a visibilidade estereoscópica no radar depende do equilíbrio entre as diferenças geométricas e as similaridades radiométricas das cenas do par (Toutin 1997, Santos et al. 1999).

Os efeitos de deslocamento de relevo produzidos nas imagens ópticas e nas de radar ocorrem em sentidos opostos. Nas imagens SAR, as estruturas verticais no terreno são deslocadas em direção ao sensor (do far para o near-range), enquanto que nas imagens ópticas, o deslocamento se dá inversamente. Ademais, o imageamento de radar produz os efeitos únicos de deslocamento das feições mais alçadas de relevo (macro-rugosidades), denominados de foreshortening e layover. A intensidade desses efeitos é inversamente proporcional ao ângulo de incidência utilizado no imageamento. A sombra de radar também é um efeito de relevo distinto do óptico, pois representa, sempre, áreas oclusas (sem nenhuma informação), enquanto no sensor óptico representa, na maioria das vezes, áreas sombreadas (não iluminadas). Típicos do radar, também, são os efeitos da micro-topografia (micro e mesorugosidades), responsáveis, em grande parte, pelo retroespalhamento do sinal de radar em áreas planas. A intensidade do efeito da micro-topografia no retroespalhamento do sinal de radar é inversamente proporcional ao ângulo de incidência utilizado (Lewis et al. 1998, Toutin \& Gray 2000). Detalhes sobre os principais fatores que modelam o retroespalhamento de imagens SAR em aplicações geológicas de ambientes na Amazônia podem ser vistos em Paradella et al. (2000).

Apesar da publicação de alguns trabalhos pioneiros, já a partir da década de 1960 (Moore 1969), não são muitas as citações na literatura sobre a estereoscopia híbrida SAR x óptico. Na estereoscopia híbrida, os aspectos mais importantes a considerar se relacionam à radiometria e à geometria das cenas do par. Por serem dados totalmente distintos e obtidos por sistemas sensores com operações diferenciadas, é necessário uma avaliação cuidadosa de ambos aspectos na composição do par estereoscópico, para que a percepção de profundidade (clareza e detalhes) não seja fortemente prejudicada. 
A correlação radiométrica entre as cenas de um par híbrido está diretamente relacionada com a visibilidade estereoscópica. $\mathrm{Na}$ busca dessa correlação alguns aspectos devem ser considerados: (1) uma imagem óptica da região do infravermelho próximo, de uma área com cobertura vegetal e relevo movimentado, é mais correlacionável radiometricamente à imagem SAR do que uma da região do visível ou pancromática. Isso porque, as imagens ópticas no infravermelho próximo tendem a realçar melhor a topografia, pelo contraste entre a alta resposta espectral da cobertura vegetal (platô do infravermelho) para as áreas iluminadas e as baixas respostas das áreas sombreadas, resultando em aparência semelhante a uma imagem SAR; (2) as imagens óptica e de radar devem ter iluminação em um mesmo sentido para que a fusão tridimensional não seja prejudicada. O azimute de iluminação das órbitas descendentes dos principais SAR orbitais é de $282^{\circ}$ (região do Equador), que é próximo à iluminação solar dos imageadores ópticos. Cenas de radar de órbitas ascendentes (azimute de iluminação de $78^{\circ}$ ) na composição de pares com imagens ópticas dificultam a visibilidade estereoscópica, pelo posicionamento inverso das áreas iluminadas e sombreadas e; (3) a incidência da iluminação SAR e o ângulo de elevação solar da imagem óptica não devem ser muito discrepantes, para que as áreas iluminadas e sombreadas sejam equivalentes.

As diferenças geométricas entre uma imagem SAR e uma óptica são bastante amplas para os efeitos de deslocamento de relevo acima de determinado datum. Para que as "distorções" entre ambas cenas não se tornem um obstáculo para a percepção de profundidade, deve-se diminuir os efeitos de relevo nos dados SAR (que são mais intensos do que no sistema óptico) pelo aumento do ângulo de incidência, ou seja, pela visão mais oblíqua do radar.

DADOS DE SENSORIAMENTO REMOTO A tabela 1 mostra as principais características das imagens utilizadas neste trabalho. A partir destas, compos-se dois pares estereoscópicos, StandardRADARSAT-1, posição 5, órbita descendente x StandardRADARSAT-1, posição 7, órbita descendente (S5D x S7D, Fig. 2) e Standard-RADARSAT-1, posição 7, órbita descendente x TMLandsat-5, banda 4 (S7D x TM4, Fig. 3), cujas análises constituem a base desta pesquisa.

A escolha do conjunto de dados de sensoriamento remoto utilizado na investigação foi baseada na análise de alguns parâmetros, com o intuito de se maximizar o conteúdo de informações geológicas a serem extraídas dos pares estereoscópicos de radar e híbrido, da área de estudo (Fig. 1). Santos et al. (1999) concluem, na mesma região de Carajás e após avaliarem diversos pares estereoscópicos com imagens Standard RADARSAT-1, que o par S5D x S7D (Fig. 2) apresentou a performance mais equilibrada em termos de interpretação geológica, nas diversas situações de relevo e de ambiente geológico analisadas. Os autores citam, entre outros, os seguintes aspectos positivos: (1) o pequeno ângulo de interseção estereoscópica do par $\left(8,0^{\circ}\right)$, associado ao mesmo azimute de iluminação das cenas descendentes $\left(282^{\circ}\right)$, tornam a visibilidade estereoscópica ótima e confortável ao observador, sob as diversas condições de relevo analisadas; (2) a Razão de Paralaxe Vertical (RPV $=0,30)$, razoável para uma configuração de mesmo sentido, permitiu um nível de detalhe muito bom na percepção de profundidade, principalmente nas áreas com relevo mais movimentado e; (3) os ângulos de incidência das cenas (S5=36/ $\left.42^{\circ}, \mathrm{S} 7=45 / 48^{\circ}\right)$ mostraram-se adequados para as variações de relevo da área, não provocando efeitos fortes de deslocamento de relevo (layover), nem áreas sombreadas (oclusas) muito extensas.
Santos et al. (2001) discutem os aspectos teóricos da estereoscopia híbrida SAR x óptico e a sua aplicação em estudos geológicos, em área teste na região de Carajás. Utilizando imagens TM-Landsat-5 e Standard RADARSAT-1, os autores concluem que o par S7D x TM4 (Fig. 3) é o mais efetivo, pelos seguintes aspectos: (1) a semelhança visual da banda 4 do TM com a imagem SAR, pelo conteúdo temático (tonalidade e textura) e realce da topografia (o alto patamar de reflectância da vegetação na banda 4 do TM realça as áreas iluminadas e favorece o contraste com as encostas sombreadas) contribui para a boa correlação radiométrica entre as cenas do par; (2) a geometria de iluminação, com incidência da imagem SAR equivalente à elevação solar do TM e mesmo sentido de iluminação nas duas cenas, apesar de uma diferença de $52^{\circ}$ nos azimutes, contribui, também, para melhorar a correlação radiométrica entre as cenas ; (3) a escolha da maior incidência entre as posições disponíveis no modo Standard (S7 = $45-48^{\circ}$ ), diminui os efeitos de deslocamento de relevo na imagem SAR e, portanto, também, as diferenças geométricas entre as cenas, facilitando a fusão tridimensional e; (4) o alto ângulo de interseção estereoscópica (acima de $45^{\circ}$ ) garante bom detalhe de percepção de profundidade.

RESULTADOS E DISCUSSÕES Os pares estereoscópicos S5D x S7D (Fig. 2) e S7D x TM4 (Fig. 3) foram analisados segundo critérios de interpretação geológica desenvolvidos para imagens ópticas orbitais e, também, aqueles adaptados às características dos dados SAR orbitais. Mediante essa análise tridimensional, comparou-se a performance de cada par na identificação dos elementos texturais de imagem e na análise de suas propriedades, que permitiram a interpretação das mais diferentes feições geológicas na área de estudo.

O par estereoscópico de radar S5D x S7D apresenta, em toda a área analisada, ótimas condições de visibilidade estereoscópica, devido a alta correlação radiométrica dada pela semelhança no conteúdo temático (mesmo sensor, modo de operação e sentido das órbitas), e pelas perspectivas de iluminação muito próximas nas duas cenas. Estas perspectivas de iluminação próximas, por outro lado, determinam paralaxes modestas para o par, que, no entanto, são adequadas para a maior parte da área, onde o relevo é mais movimentado e o detalhe de percepção de profundidade é muito bom. Considerando estas características radiométricas e geométricas, a performance do par foi avaliada estereoscopicamente tendo como base todas as feições geológicas (unidades, contatos e estruturas) cartografadas na figura 1. Estas feições foram classificadas em termos de sua nitidez e facilidade de caracterização na interpretação tridimensional, dentro de uma escala variando de ótimo a sem definição (Tab. 2).

A interpretação geológica do par estereoscópico de radar S5D x S7D (Fig. 2) permitiu as seguintes observações:

(1) - Os limites da Formação Águas Claras com o Granito Central e, também, o contato entre os membros dessa unidade, são, entre todos, os mais bem definidos na estereoscopia do par de radar. Constituem proeminentes quebras negativas, em um relevo fortemente assimétrico, com rios encaixados em vales escarpados . O caráter fortemente assimétrico do relevo reflete a atitude subhorizontal destas rochas. O contato com o granito é menos definido a sul, quando tende a ser paralelo à iluminação (Fig. 2, letra A). A maior parte dos limites tectônicos da Formação Águas Claras com o Grupo Grão-Pará é nítida e dada por proeminentes alinhamentos de drenagem, apesar do ângulo pequeno entre essas feições e a iluminação. Apenas quando esse paralelismo é 
Athos Ribeiro dos Santos et al.

Tabela 1 - Principais características dos dados de sensoriamento remoto utilizados na pesquisa.

\begin{tabular}{|c|c|c|c|c|c|c|}
\hline $\begin{array}{c}\text { Plataforma/ } \\
\text { Sensor }\end{array}$ & $\begin{array}{c}\text { Banda/ } \\
\text { Posição }\end{array}$ & Data & Escala & $\begin{array}{c}\text { Resolução } \\
\text { Espacial (m) }\end{array}$ & $\begin{array}{c}\text { Elev. Solar***/ } \\
\text { Incidência }\end{array}$ & $\begin{array}{c}\text { Az. Solar/ } \\
\text { Az. de } \\
\text { Iluminação }\end{array}$ \\
\hline \hline $\begin{array}{c}\text { Landsat-5/ } \\
\text { TM 226/064 }\end{array}$ & TM4 & $22 / 06 / 86$ & $1: 250.000$ & 30 & $43^{\circ}$ & $50^{\circ}\left(230^{\circ}\right)$ \\
\hline $\begin{array}{c}\text { RAD ARSA T-1/ } \\
\text { SAR-C Standard }\end{array}$ & $\mathrm{S}^{*} 5 \mathrm{D} * *$ & $31 / 05 / 96$ & $1: 250.000$ & $24,2 \times 27,0$ & $36 / 42^{\circ}$ & $282^{\circ}$ \\
\cline { 2 - 6 } & S*7D** & $11 / 09 / 96$ & $1: 250.000$ & $22,09 \times 27,0$ & $45 / 48^{\circ}$ & $282^{\circ}$ \\
\hline
\end{tabular}

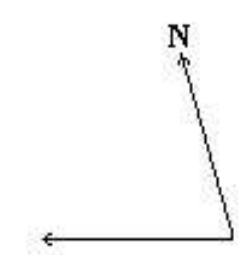

Ilum.

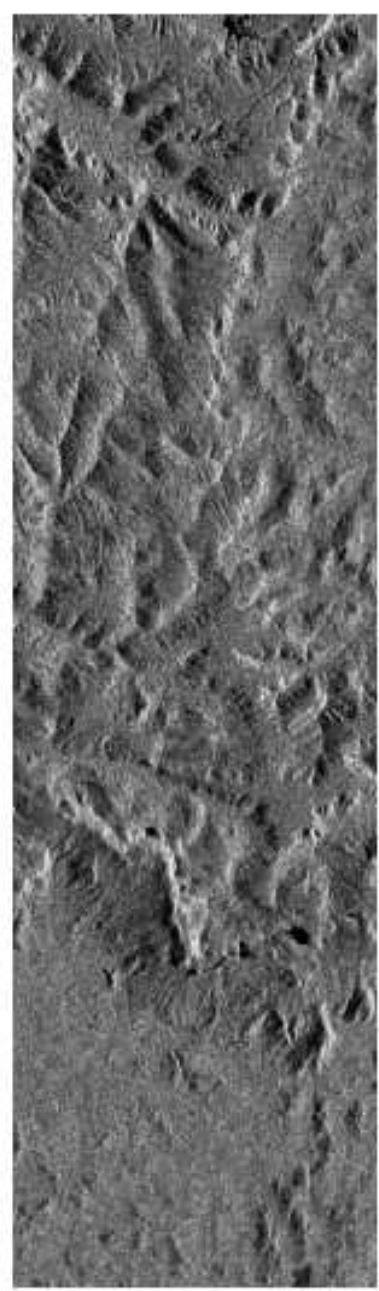

0

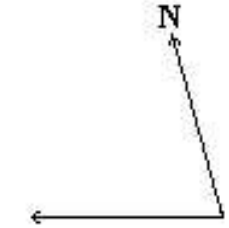

Ilum.
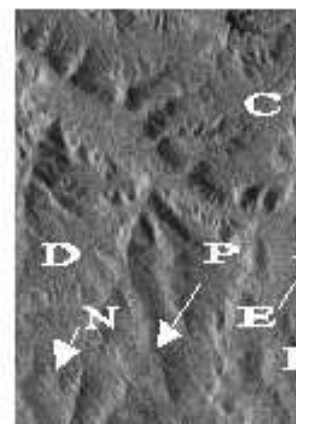

6y
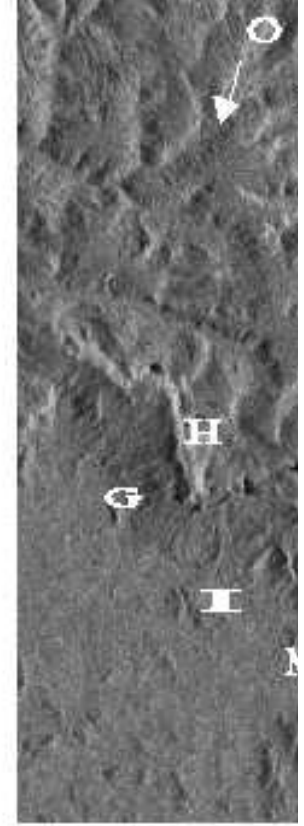

$10 \mathrm{Km}$

Figura 2 - Par estereoscópico de radar S5D x S7D. As letras são discutidas no texto.

total, o contato perde definição (Fig. 2, letra B);

(2) - A extensa ocorrência de lateritas sobre a Formação Águas Claras é bem caracterizada no par estereoscópico de radar, principalmente na porção norte, pela sua forma plana, posicionada no topo dos morros, representando quebras positivas de um relevo

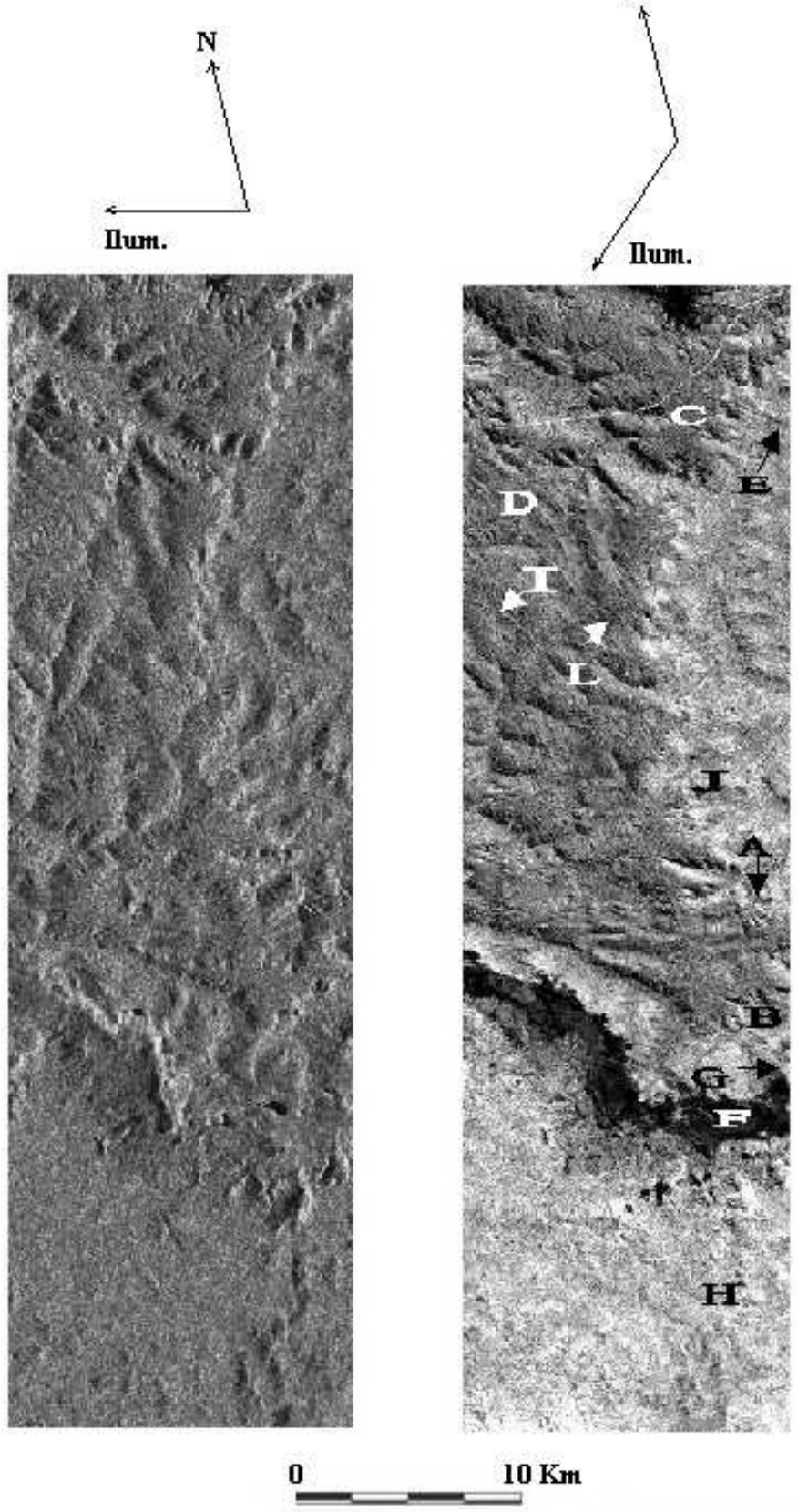

Figura 3 - Par estereoscópico híbrido S7D x TM4. As letras são discutidas no texto.

fortemente assimétrico (Fig. 2, letra C). As ocorrências de laterita situadas a sudoeste das anteriores, por terem sido mais erodidas, perdem um pouco de definição (Fig. 2, letra D);

(3) - Subdivisões internas ao Granito Central de Carajás (Fig. 1) foram propostas por Paradella et al. (1998), baseadas em padrões 
de produtos integrados de radar com dados aerogamaespectrométricos, espacialmente correlacionados com dados litológicos de campo. O bom detalhe de percepção de profundidade do par estereoscópico permitiu caracterizar diferenças sutis de relevo (que no todo é ondulado, com os morros tendendo à simétricos) e alinhamento de cristas que marcam grande parte do contato entre corpos de anfibólio-biotita-monzogranito e biotita-anfiboliosienogranito/biotita-monzogranito/biotita-sienogranito proposta pelos autores (Fig. 2, letra E). Contudo, o limite proposto entre as unidades baixo gama CT e anfibólio-biotita-monzogranito, e definido principalmente por atributos radiométricos, não foi passível de definição com o estéreo-par (Fig. 2, letra F).

(4) - O Grupo Grão-Pará (formações Parauapebas e Carajás) tem contatos tectônicos, a norte com a Formação Águas Claras e, a sul, com o Complexo Xingu, marcado por uma quebra negativa esterescopicamente bem definida e que limita o relevo montanhoso da Serra com a planície do entorno (Fig. 2, letra G). A área de ocorrência do Grupo Grão-Pará é claramente diferenciada das unidades vizinhas pelo caráter fortemente anisotrópico de feições lineares de drenagem e relevo, bem definidas estereoscopicamente, associadas à foliação cataclástico-milonítica WNW-ESE . A separação entre as formações Parauapebas e Carajás, esta última com ocorrências na Serra Sul (Fig. 2, letra H) e outras menores, não foi possível na análise do par estereoscópico de radar. Isto deve-se à extrema homogeneidade das propriedades texturais de drenagem e de relevo e das tonalidades de cinza, em toda área de ocorrência do Grupo Grão-Pará;

(5) - O Complexo Xingu é facilmente diferenciado das outras unidades, à norte, pelo seu característico relevo plano e pela quebra negativa do seu limite com a Serra dos Carajás. A identificação de detalhes na sua área de ocorrência, no entanto, é prejudicada pela iluminação muito oblíqua das cenas do estéreo-par, que não favorecem o efeito da micro-topografia no retroespalhamento do sinal de radar;

(6) - A unidade que, na figura 1, está cartografada como área com alta resposta gamaespectrométrica para urânio, com ocorrências na região sul da área de estudo (Fig. 2, letra I), não apresentou resposta no estéreo-par de radar que permitisse diferenciá-la das áreas de ocorrência do Complexo Xingu;

(7) - O azimute de iluminação das cenas do par estereoscópico de radar $\left(282^{\circ}\right)$ não é muito favorável ao realce do trend estrutural regional NW-SE a WNW-ESE, pelo pequeno ângulo entre ambas direções. No entanto, essas estruturas, dada a sua intensidade e continuidade, são bem realçadas em quase toda a área, principalmente na região da Serra. A exceção ocorre quando a paralelização entre iluminação e estrutura é, praticamente, total (Fig. 2, letra J). As principais estruturas com esta orientação são representadas pelo braço sul da Falha de Carajás, que claramente tem continuidade no Granito Central ( Fig. 2, letra L) e pelos limites tectônicos do Grupo Grão-Pará, além da bem desenvolvida foliação de cisalhamento associada. Dificuldades na definição de estruturas relacionadas ao trend estrutural foram encontradas apenas na área de ocorrência do Complexo Xingu, onde a característica desfavorável do azimute de iluminação soma-se à topografia plana do relevo (Fig. 2, letra M);

(8) - Uma das feições estruturais mais marcantes na área de ocorrência da Formação Águas Claras é o sistema de fraturas e diques básicos associados de direção NNW-SSE. Estas estruturas estão caracterizadas no par estereoscópico de radar por feições lineares de drenagem muito bem definidas pela geometria de iluminação (incidência e azimute) favorável (Fig. 2, letra N);
(9) - O sistema de fraturas NE-SW, que ocorre principalmente no Granito Central, tem ótima caracterização no par estereoscópico de radar através de alinhamentos contínuos realçados (de drenagem e de relevo), também, pela geometria de iluminação favorável das cenas do par (Fig. 2, letra O);

(10) - Extensos alinhamentos de drenagem e de relevo cortando toda a área na direção N-S (Fig. 2, letra P), bem realçados pela posição quase perpendicular à iluminação das cenas, constituem um importante sistema de fraturas na área.

O estéreo-par híbrido S7D x TM4 não apresenta, de modo geral, visibilidade estereoscópica tão boa quanto a do par de radar, pelas amplas diferenças de radiometria e geometria que caracterizam esses sensores. A adoção de critérios anteriormente discutidos, que buscam minimizar essas diferenças, permitiu que o par apresentasse uma boa e confortável visibilidade estereoscópica, em grande parte da área de estudo. Regiões com problemas serão abordadas mais adiante. O par estereoscópico híbrido foi interpretado da mesma forma e com os mesmos critérios de classificação de feições geológicas utilizados no par estereoscópico de radar.

A interpretação geológica do par S7D x TM4 (Fig. 3), quando comparada com os resultados obtidos com o estéreo-par de radar S5D x S7D, permitiu as seguintes observações:

(1) - Os contatos da Formação Águas Claras têm ótima definição no par estereoscópico, pelos mesmos motivos observados no par de radar (proeminentes quebras negativas, alinhamentos, etc.). As deficiências na definição dos contatos desta unidade descritas na análise anterior, foram sanadas neste par pela adição de uma nova perspectiva à iluminação SAR, dada pela iluminação solar do TM-Landsat-5 (Fig. 3, letras A, B). Alem disso, o contato da Formação Águas Claras com o Granito Central marca, no TM4, o limite de uma significativa variação radiométrica entre ambas unidades (diferentes tons de cinza), o que não ocorre na imagem S7D. $\mathrm{Na}$ análise estereoscópica, esta diferença de tonalidade realça o limite entre as duas unidades, sem perda expressiva de visibilidade estereoscópica;

(2) - Houve um evidente ganho de definição nos limites das ocorrências de laterita neste par estereoscópico híbrido, em relação ao estéreo-par SAR. Isso se dá tanto nas ocorrências mais a norte (Fig. 3, letra C), onde a definição passa de boa para ótima (Tab. 2), como naquelas à sudoeste das anteriores (Fig. 3, letra D), onde algumas ocorrências classificadas anteriormente como de definição regular, passam a ter uma expressão boa (Tab. 2). Este ganho deve-se as diferentes contribuições de cada um dos sensores: a geometria superficial (relevo plano) pelo S7D e o mapeamento das respostas espectrais superficiais da vegetação (tons de cinza) pelo TM4;

(3) - Com relação as subdivisões internas do Granito Central, como cartografado na figura 1 , a contribuição do par estereoscópico híbrido foi pequena. A única contribuição notável, em relação ao par anterior, ocorreu na porção norte do contato entre as unidades Anfibólio-biotita-monzogranito e Biotita-anfibólio-sienogranito/ biotita-sienogranito (Fig. 3, letra E). A identificação deste limite deve-se mais aos tons claros de cinza (alta reflectância) no Granito Central, que realçam as variações topográficas, do que ao azimute solar doTM4, que é quase paralelo a este contato;

(4) - Os contatos do Grupo Grão-Pará são bem definidos, principalmente à norte, com algum ganho em relação ao par de radar, obtido pelos diferentes azimutes de iluminação das duas cenas do par híbrido. A principal diferença, no entanto, refere-se à área de ocorrência da Formação Carajás. Aqui, dois aspectos devem ser considerados. Primeiro, observa-se que monoscopicamente a área 
de ocorrência da Formação Carajás, principalmente na Serra Sul (Fig. 3, letra F), é facilmente identificável pelo seu contrastante tom negro na imagem TM4. Esta tonalidade deve-se à quase total ausência de vegetação nessas áreas e a forte absorção da radiação eletromagnética pelo ferro nessa banda do espectro eletromagnético. O segundo aspecto refere-se a grande disparidade radiométrica entre as cenas do par estereoscópico híbrido (cinza claro no S7D e negro no TM4), resultando em visibilidade estereoscópica ruim. As dificuldades de fusão tridimensional são, inicialmente, muito grandes, requerendo treino e experiência neste tipo de análise para alcançá-la, ainda assim com visibilidade estereoscópica ruim;

(5) - O Complexo Xingu apresentou boa caracterização no estéreo-par híbrido, pelos mesmos motivos expostos para o par de radar. A alta elevação solar da cena do TM e a elevada incidência na imagem SAR prejudicaram, também, a percepção de detalhes na área de ocorrência do Complexo Xingu;

(6) - A unidade denominada na figura 1 como área com alta resposta gama urânio, pelos motivos descritos para o par de radar, não pode ser individualizada no par estereoscópico híbrido;

(7) - A utilização de dois azimutes de iluminação $\left(282^{\circ}\right.$ e $\left.230^{\circ}\right)$ pelas duas cenas do par estereoscópico híbrido, resultou em algum ganho no realce do trend estrutural regional (NW-SE a WNW-ESE), em relação ao par de radar. Esse ganho é mais notável na região da Serra, na área de ocorrência do Grupo Grão-Pará, onde o trend estrutural WNW-ESE é sub-paralelo à iluminação do radar (Fig. 3, letra G). Na área de planície no entorno da Serra, por outro lado, houve alguma perda na definição do trend regional (Fig. 3, letra H). Nesse sentido, alguns aspectos devem ser considerados. Por ser a área bastante plana e os ângulos de incidência e de elevação solar relativamente altos (respectivamente, $45-48^{\circ} \mathrm{e}$ $43^{\circ}$ ), os efeitos de micro-topografia no caso dos dados SAR e os de sombreamento nos dados ópticos, foram insignificantes, não resultando em qualquer ganho de realce, apesar do papel complementar dos dois azimutes de iluminação das cenas do par. $\mathrm{O}$ aspecto negativo, que resultou na perda de realce do trend em relação ao par anterior, está relacionado à intensa atividade antrópica nesta região. A atividade antrópica, normalmente registrada em tonalidades (tons escuros no S7D e claros no TM4) e tamanhos e formas diferentes (diferentes datas de aquisição) nas duas cenas do par, prejudicou significativamente a visibilidade estereoscópica;

(8) - O intenso fraturamento NNW-SSE na área de ocorrência da Formação Águas Claras, a exemplo do par estereoscópico de radar, apresentou ótima definição no par híbrido (Fig. 3, letra I);

(9) - A boa definição do sistema de fraturas NE-SW no par estereoscópico híbrido é dada pelo azimute de iluminação quase perpendicular a esta direção da imagem SAR. Estas estruturas estão bastante atenuadas na imagem óptica devido ao pequeno ângulo com o azimute solar da cena (Fig. 3, letra J);

(10) - As extensas fraturas N-S apresentam boa definição no par estereoscópico híbrido devido aos azimutes de iluminação favoráveis, tanto da imagem S7D quanto da cena TM4 (Fig. 3, letra L).

A tabela 2 resume os resultados de performance dos pares estereoscópicos S5D x S7D e S7D x TM4 na interpretação das feições geológicas analisadas. A seqüência das letras $(\mathrm{O}, \mathrm{B}, \mathrm{R}, \mathrm{e}$ $\mathrm{SD}$ ) que classificam um aspecto analisado (ocorrência, contato ou definição da estrutura) obedece a ordem de maior para menor ocorrência (p. ex.: contatos $\mathrm{O}-\mathrm{B}$, a classificação indica que a maior extensão dos contatos dessa unidade foi caracterizado, em termos de definição, como ótimo e a menor parte restante como bom).
CONCLUSÕES A pesquisa evidenciou a importância da estereoscopia, de radar e híbrida, na análise de dados de sensoriamento remoto orbital, como forma de melhorar a sua performance em termos de interpretação geológica. Para que se obtenha bons resultados, no entanto, é fundamental que se considere as características de cada uma das cenas do par, principalmente as de geometria e radiometria, que estão relacionadas ao tipo de sensor, região do espectro eletromagnético, geometria de visada/iluminação, etc., assim como as características fisiográficas, geológicas e de cobertura vegetal da área de estudo. Com relação aos pares estereoscópicos analisados, foi possível concluir que:

Tabela 2 - Performance dos pares estereoscópicos em relação à geologia da área de estudo.

\begin{tabular}{|c|c|c|c|}
\hline $\begin{array}{l}\text { Unidades/Estruturas } \\
\text { Geológicas }\end{array}$ & Aspectos Analisados & S5D x S7D & S7D x TM4 \\
\hline \multirow{2}{*}{ (1) Formação Águas Claras } & Ocorrências & $\mathrm{O}$ & $\mathrm{O}$ \\
\hline & Contatos & $\mathrm{O}-\mathrm{B}$ & $\mathrm{O}$ \\
\hline \multirow{2}{*}{ (2) Lateritas } & Ocorrências & $\mathrm{B}$ & $\mathrm{O}$ \\
\hline & Contatos & $B-R$ & $\mathrm{O}-\mathrm{B}$ \\
\hline \multirow{2}{*}{ (3a) Granito Central - Unidade 1* } & Ocorrências & SD & SD \\
\hline & Contatos & $\mathrm{SD}-\mathrm{B}-\mathrm{R}$ & $\mathrm{O}-\mathrm{SD}$ \\
\hline \multirow{2}{*}{ (3b) Granito Central - Unidade $2 * *$} & Ocorrências & $\mathrm{R}$ & $\mathrm{R}$ \\
\hline & Contatos & $\mathrm{O}-\mathrm{R}-\mathrm{SD}-\mathrm{B}$ & $\mathrm{O}-\mathrm{R}-\mathrm{SD}$ \\
\hline \multirow{2}{*}{ (3c) Granito Central - Unidade $3 * * *$} & Ocorrências & $\mathrm{R}$ & $\mathrm{R}$ \\
\hline & Contatos & $\mathrm{R}-\mathrm{SD}$ & $\mathrm{R}$ \\
\hline \multirow{2}{*}{ (4a) Grupo Grão-Pará } & Ocorrências & B & B \\
\hline & Contatos & $\mathrm{O}-\mathrm{B}$ & $\mathrm{O}-\mathrm{B}$ \\
\hline \multirow{2}{*}{ (4b) Formação Carajás } & Ocorrências & SD & $\mathrm{R}$ \\
\hline & Contatos & SD & $\mathrm{R}$ \\
\hline \multirow{2}{*}{ (5) Complexo Xingu } & Ocorrências & $\mathrm{B}-\mathrm{R}$ & $\mathrm{B}-\mathrm{R}$ \\
\hline & Contatos & B & B \\
\hline \multirow{2}{*}{ (6) Unidade com alta resposta Urânio } & Ocorrências & SD & SD \\
\hline & Contatos & SD & SD \\
\hline (7) Trend Estrutural & \multirow{4}{*}{ DEFINIÇÃO } & $\mathrm{O}-\mathrm{B}-\mathrm{R}$ & $\mathrm{O}-\mathrm{R}-\mathrm{B}$ \\
\hline (8) Fraturas NNW-SSE & & $\mathrm{O}$ & $\mathrm{O}$ \\
\hline (9) Fraturas NE-SW & & $\mathrm{O}$ & B \\
\hline (10) Fraturas N-S & & B & B \\
\hline
\end{tabular}

$\mathrm{O}=$ ótimo $\mathrm{B}=$ bom $\mathrm{R}=$ regular $\mathrm{SD}=$ sem definição

*Unidade desconhecida baixo gama CT

**Anfibólio-biotita-monzogranito

***Biotita-anfibólio-sienogranito/biotita-monzogranito/biotitasienogranito

(1) - A visibilidade estereoscópica foi melhor no par S5D x S7D em relação ao par híbrido. A perda de visibilidade estereoscópica do par S7D x TM4 deveu-se a pior correlação radiométrica de suas cenas, em relação ao par de radar, por se tratarem de produtos de sensores com diferentes radiometrias. Esta perda, no entanto, só comprometeu a visibilidade onde a disparidade radiométrica entre as cenas do estéreo-par híbrido era muito grande, como na área de ocorrência da Formação Carajás;

(2) O detalhe de percepção de profundidade nas áreas de relevo mais movimentado foi muito bom e equivalente nos dois pares, apesar do maior ângulo de interseção estereoscópica (maior paralaxe) do par híbrido. Nas áreas mais planas a percepção dos detalhes de profundidade foi menos eficiente, devido a visão muito oblíqua das cenas de radar e a elevação solar alta (para uma área plana), que minimizaram, respectivamente, os efeitos de microtopografia e sombreamento;

(3) O par estereoscópico híbrido apresentou uma importante vantagem em relação ao par de radar, que foi dada pelo caráter complementar das informações fornecidas pelos dois sistemas sensores: a geometria da superfície modelada pelo SAR e o mapeamento das respostas espectrais dos materiais superficiais dado pelo sensor óptico. Muitas vezes, as formas (S7D) e os tons de cinza (TM4) se fundiram na visão tridimensional para dar mais 
subsídios à interpretação geológica, como, por exemplo, no caso das lateritas ou do Granito Central;

(4) A utilização de dois azimutes de iluminação no par estereoscópico híbrido - em um mesmo sentido, porém com um intervalo de $52^{\circ}$ - foi, também, um aspecto positivo no realce das estruturas planares, em relação ao par estereoscópico de radar. As estruturas WNW-ESE que se mostraram atenuadas ou mesmo suprimidas nas cenas de radar, apresentaram um bom realce na imagem TM4, contribuindo para que elas tivessem uma boa caracterização na análise do par estereoscópico híbrido e;

(5) O balanço final indicou uma maior potencialidade da estereoscopia híbrida em relação à de radar, devida, basicamente, pela possibilidade de utilização de conjuntos de dados diferentes que se complementam na interpretação geológica. Por outro lado, a estereoscopia híbrida requer maiores cuidados na composição dos pares, buscando diminuir as amplas diferenças (radiométricas e geométricas) entre os dois conjuntos de dados, que são inerentes aos próprios sistemas sensores, para que a percepção tridimensional não seja comprometida significativamente.

Agradecimentos À Canadian Space Agency (CSA) pelas imagens RADARSAT-1através do Programa ADRO, ao CNPq pela Bolsa de Produtividade em Pesquisa do segundo autor (Processo CNPq 300985/90-80) e aos revisores da RBG pelas sugestões.

\section{Referências}

Almeida F.F.M., Hasui Y., Brito Neves B.B., Fuck R.A. 1981. Brazilian Structural Provinces: an introduction. Earth Sci. Review, 17:1-9.

Araújo O.J.B., Maia R.G.N. 1991. Serra dos Carajás, Folha SB-22-Z-A. Relatório Final. CPRM, Rio de Janeiro, Brasil, 136p.

Cordani U.G., Brito Neves B.B. 1982. The geological evolution of South America during the Archean and Early Proterozoic. Rev. Bras. Geoc., 12:78-88.

Dall'Agnol R., Costi R., Leite A.A.S., Magalhães M., Teixeira N.P. 1999. Rapakivi granites from Brazil and adjacent areas. Prec. Res., 95:9-39.

DOCEGEO 1988. Revisão litoestrátigráfica da Província Mineral de Carajás. In: SBG, Congr. Bras. Geol., 25, Belém, Anexo, 10-54.

Harris J., Bowie C., Rencz A., Graham D. 1994. Computer-enhancement technique for the integration of remotely sensed, geophysical, and thematic data for the geosciences. Can. J. Rem. Sensing, 20:210-221.

Hasui Y., Haraly N.L.E., Schobbenhaus C. 1984. Elementos geofísicos e geológicos da região Amazônica: subsídios para o modelo geotectônico. In: SBG, Simpósio de Geologia da Amazônia, 1, Manaus, Anais, 1:129-141.

Hasui Y. \& Haraly N.L.E. 1985. Integração de informações geofísicas e geológicas na definição de estruturas crustais brasileiras. Rev. Bras. Geofisica, 4:248-249.

La Prade G. 1963. An analytical and experimental study of stereo for radar. Photogrammetric Engineering, 29:294-300.

Lewis A.J., Henderson F.M., Holcomb D.W. (Contributing Author) 1998. Radar fundamentals: the Geoscience Perspective. In: F.M. Henderson \& A.J. Lewis (eds.) Principles Applications of image Radar, Manual of Remote Sensing. New York. Am. Soc. Phot. and Rem. Sens., 131181.

Machado N., Lindenmayer Z., Krough T.E., Lindenmayer D. 1991. U$\mathrm{Pb}$ geochronology of Archean magmatism and basement reactivation in the Carajás area, Amazon Shield, Brazil. Prec. Res., 49:329-354.

Moore R.K. 1969. Heights from simultaneous radar and infrared. Photogr. Engineering, 5:649- 651.

Paradella W.R., Silva M.F.F., Rosa N.A., Kushigbor C.A. 1994. A geobotanical approach to the tropical rain forest environment of the Carajás Mineral Province (Amazon Region, Brazil), based on digital TM-Landsat and DEM data. Intern. J. Remote Sensing, 15:16331648.

Paradella W.R., Bignelli P.A., Veneziani P., Pietsch R.W., Toutin T. 1997. Airborne and spaceborne Synthetic Aperture Radar (SAR) integration with Landsat TM and Gamma Ray Spectrometry for geological mapping in a tropical rainforest environment, the Carajás Mineral Province, Brazil. Intern. J. Rem. Sensing, 18:1483-1501.

Paradella W.R., Santos A.R., Dall'Agnol R., Pietsch R.W., Sant'Anna M.V. 1998. A geological investigation based on airborne (SAREX) and spaceborne (RADARSAT-1) SAR integrated products in the Central Serra dos Carajás Granite area, Brazil. Can. J. Rem. Sensing, 24:376-392.

Paradella W.R., Santos A.R., Veneziani P., Morais M.C. 2000. Synthetic Aperture Radar for geological applications in the moist tropics: experiences from the Brazilian Amazon Region. Rev. Bras. Geoc. 30:538-543.

Pinheiro R.V.L. 1997. Reactivation history of the Carajás and Cinzento Strike Slip Systems, Amazon, Brazil. University of Durham, UK, Ph.D Dissertation, 408p.

Pinheiro R.V.L. \& Holdsworth R.E. 2000. Evolução tectonoestratigráfica dos sistemas transcorrentes Carajás e Cinzento, Cinturão Itacaiúnas, na borda leste do Craton Amazônico, Pará. Rev. Bras. Geoc., 30:59750 .

Santos A.R., Paradella W.R., Veneziani, P., Morais M.C. 1999. A estereoscopia com imagens RADARSAT-1: uma avaliação geológica na Província Mineral de Carajás. Rev. Bras. Geoc., 29:627-632.

Santos A.R., Paradella W.R., Veneziani P., Morais M.C.2001. Análise estereoscópica através da combinação de dados SAR e ópticos: Fundamentação e avaliação em estudos geológicos na região de Carajás. In: SELPER/INPE, Simpósio Brasileiro de Sensoriamento Remoto, 10 , Foz de Iguaçu, $C D-R O M$.

Teixeira W., Tassinari C.C.G., Cordani U.G., Kawashita K. 1989. A review of the geochronology of the Amazonian Craton: tectonic implications. Prec. Res., 42:213-217.

Toutin T. 1997. Évaluation de la géométrie des images RADARSAT: Premiers résultats. In: ADRO, Intern. Symp. Geomatics in the Era of RADARSAT, Ottawa, Canada, CD-ROM.

Toutin T. 2000. Stereo mapping with SPOT-P and ERS-1 SAR images. Intern. J. Rem. Sensing, 21:1657-1674.

Toutin T. \& Gray L. 2000. State-of-the-art of elevation from satellite SAR data. ISPRS J. Photogram. Rem. Sensing, 55:13-33.

Toutin T. \& Vester C. 1997. Understanding RADARSAT data in stereo. In: ADRO, Intern. Symp. Geomatics in the Era of RADARSAT, Ottawa, Canada, $C D-R O M$.

Veneziani P., Santos A.R., Paradella W.R. 2002. A evolução tectonoestratigráfica da Província Mineral de Carajás: uma interpretação através de dados de sensoriamento remoto óptico (TM-Landsat) e das microondas (SAR C-RADARSAT-1). Rev. Bras. Geoc. (submetido).

Manuscrito SR-21

Recebido em 20 de setembro de 2002

Revisão dos autores em 10 de março de 2003

Revisão aceita em 20 de abril de 2003 